\title{
Reduction of vibration and noise pollution from agricultural tractor engine using novelPine oil and soapnut oil methyl ester as fuel
}

Venkatesan Vedhagiri ( $\sim$ venkatesanv81@gmail.com )

GKM College of Engineering and Technology: GKM College of Engineering https://orcid.org/00000003-2047-8020

Nallusamy Nallusamy

SSN College of Engineering: Sri Sivasubramaniya Nadar College of Engineering

Perumal Nagapandiselvi

SSN College of Engineering: Sri Sivasubramaniya Nadar College of Engineering

\section{Research Article}

Keywords: Tractor engines, Pine oil, Soapnut oil biodiesel, Vibration, Noise reduction, environmental pollution

Posted Date: February 16th, 2022

DOI: https://doi.org/10.21203/rs.3.rs-1181426/v1

License: (c) (i) This work is licensed under a Creative Commons Attribution 4.0 International License. Read Full License 


\section{Abstract}

The exhaust emissions from automotive diesel engines are successfully controlled over the years by adopting different combustion strategies and after treatment devices. Whereas, the combustion induced vibration and noise which is one of the major polluting source in off-road vehicle engines were not yet optimized. In the present study, a twin cylinder, Simpson's S-217 tractor diesel engine was used to evaluate the performance, combustion, vibration and noise characteristics using biofuel blends. For this study, the blends of pine oil - soapnut oil biodiesel (P75SNB25), diesel - soapnut oil biodiesel (SNB20) and diesel were used as fuel. The pine oil used in the research was purchased and used in its neat form. The soapnut oil was extracted from the soapnut seeds by cold pressing method and trans-esterified in two stages using methanol and catalysts. The performance and combustion characteristics of the blend P75SNB25 was superior to diesel and the blend SNB20 was slightly inferior to diesel. For the blend P75SNB25 the amplitude of acceleration with respect to time was reduced by $19.48 \%$ and $11.58 \%$ at no load and full load respectively. For the blend SNB20 the amplitude of acceleration showed a reduction of $14.27 \%$ and $9.46 \%$ at no load and full load respectively in comparison with diesel operation. The noise emission for the blends P75SNB25 and SNB20 was decreased by a maximum of $2.34 \%$ at different engine loads compared to diesel operation.

\section{Introduction}

Diesel engines or self-ignition engines are the most preferred engine type for powering transport, agricultural, construction and mining vehicles because of its greater thermal efficiency. Due to the exhaustion of conventional fuel resources and increasing greenhouse gas emission to the environment, the efforts are taken place worldwide towards the development of new, renewable and green fuels as alternative to diesel and new power-trains alternative to internal combustion engines. The refinement of noise, vibration and harshness are the key targets for the diesel engine powered vehicles in the future as it might have direct impact on the users. Most of the engine researchers investigated the feasibility of using biofuels in the compression ignition engines from the perspective of its performance, combustion and emission. But the long term negative effects such as engine life and durability of their components while using biofuels are yet to be investigated [Calık 2018]. The operating parameters of the engine and the quality of fuel used may lead either erratic or smooth combustion. The erratic combustion inside the combustion chamber results in knocking as a result the engine tends to vibrate more [Uludamar et al. 2017]. Unwarranted engine vibrations will shrink the lifespan of the engine components and increases the maintenance. However, it is inevitable for the diesel engines to 2operate without vibration and noise. Noise is caused by the rapid pressure rise in the combustion chamber during combustion and by moving parts.

Hence, the comprehensive analysis is necessary to understand the causes of vibration and noise in the engine in order to avert their generation. Also the effect of using biofuels on engine vibration is essential so as to decide their sustainability. Vibration analysis aims to determine the rate of oscillations/ frequency about equilibrium. The number of times a complete motion cycle occurs per second is the 
frequency of vibration and is measured in hertz $(\mathrm{Hz})$. Various factors which affect the engine vibration and noise, the impact of fuel characteristics and problems associated with excessive noise and vibration are reported by many researchers.

The effect of injection pressure and the quantity of fuel injected on engine vibration was studied by using Classical Fourier transforms analysis and time-frequency analysis. It was reported that there is a degree of correlation between injection parameters, in-cylinder pressure and vibration signals [Carlucci et al. 2005]. The effect of higher biodiesel blends with hydrogen addition was investigated in a four stroke, single cylinder diesel engine runs at a constant speed of $1500 \mathrm{rpm}$. The blends of $50 \%, 75 \%$ and $100 \%$ by volume of Pongamia Pinnata and Tung oil with diesel were used as fuel. The results revealed that the reduction in vibration acceleration by $8.15 \%, 9.02 \%, 5.84 \%, 8.70 \%$ for the blends PP50, PP75, T50 and T75 respectively was achieved with the addition of hydrogen into the intake manifold [Celebi et al. 2017]. The engine vibration and acoustic signals were used as a diagnostic tool for monitoring the working of diesel engine and its combustion quality and found a viable correlation to predict indicated mean effective pressure inside the cylinders [Barelli et al. 2009]. From the experiments, the greater vibration signal peaks were recorded with an increase in load.

Investigations were carried out to study the influence of waste cooking oil biodiesel blend on the vibration and noise of a twin cylinder diesel engine used in a small car. Accelerometer and microphone were used to record vibration and noise signals from the engine running on three different blends namely B10, B20 and B40 at the speeds of $2400 \mathrm{rpm}$ to $3600 \mathrm{rpm}$. For all the blends, the amplitude of vibration and noise increases with the increase of engine speed. The blend B40 is characterized by highest values of accelerometer RMS and lowest noise index at higher load and speed [Chiatti et al. 2016]. The effects of using mustard oil biodiesel (MOB) and hydrogen gas mixture on vibration, noise and emission were studied in a Mitsubishi Canter, 4 cylinder direct injection diesel engine. The use of neat biodiesel resulted significant reduction in engine vibration and noise level due to the better combustion of oxygenated fuel. With the addition of a constant flow rate of $5 \mathrm{lit} / \mathrm{min}$ hydrogen into the intake manifold reduced the vibration and noise level further compared to diesel. This is due to the finer operational stability of the engine achieved with easier ignition of fuel [Tuccar 2018]. Experiments were carried out in a single cylinder direct injection diesel engine using Jatropha Methyl Ester (JME) biodiesel with 100 ppm concentration of Zinc Oxide ( $\mathrm{ZnO}$ ) Nano particles of 20 and $40 \mathrm{~nm}$ sizes along with hydrogen as secondary fuel to study the vibration level. Using Artificial Neural Network, a model was developed to predict RMS velocity. From the results, it was concluded that the reduction in vibration is attributed to increase in Nano size. It was concluded that the blends B30JME40 (JME 30\%: Diesel 70\%: ZnO 40) and B20JME40 (JME 20\%: Diesel 80\%: ZnO 40) are best fuel blend with least vibration at all loads [Javed et al. 2016]. Similarly lowest level of vibration was observed while testing a single cylinder diesel engine using cottonseed oil methyl ester blend B20 [Sarıdemir and Agbulut 2019].

Experimental investigations were carried out on a four cylinder, turbocharged, common rail direct injection diesel engine to study the vibration characteristics using coconut biodiesel- diesel blends at different loads. It was observed that the blend B50 shows a significant reduction in RMS of accelerations than 
diesel at all loading conditions. A maximum reduction in RMS acceleration was observed as $13.7 \%$ with the use of B50 at full load condition compared to diesel [How et al. 2014]. The comprehensive literature review concludes that there is still a research scope to study the vibration and noise characteristics of offroad vehicle engines running on biodiesel fuels. In this research work, the effects of biofuel on the engine performance, combustion, vibration and noise were investigated in an agricultural tractor engine. The blends of pine oil-soapnut oil biodiesel and diesel-soapnut oil biodiesel were tested in the unmodified diesel engine used in agricultural tractors and the results were compared with the standard diesel operation.

\section{Materials And Methods}

\subsection{Soapnut oil biodiesel preparation}

The pericarp of the soapnut is used as natural detergents to wash fabrics, bathing and to produce traditional medicines and the seeds remains unutilized. The oil containing seeds were collected for free of cost from a natural detergent industry in Chennai. The seed kernels were crushed in cold press to extract soapnut oil. The oil yield of $44.2 \%$ by weight of soapnut kernel was achieved, which is competitive to some other nonedible seeds such as soybean, rubber seed, corn etc. [Silva et al. 2014]. Earlier works on the characterization of soapnut oil reported that their acid value is about $13.4 \mathrm{mg} \mathrm{KOH} / \mathrm{g}$ in which the conversion of soapnut oil into soapnut oil biodiesel was done by acid catalyst transesterification followed by base catalyst transesterification [Chen et al. 2012]. The transesterification was carried out using methanol and soapnut oil at 6: 1 volumetric ratio. The mixture is heated up to $55^{\circ} \mathrm{C}$ and $1 \%$ weight of anhydrous Sulphuric acid is added to the mixture drop-wise. During the reaction time of 60 minutes, the mixture is stirred using a motorized stirrer at $600 \mathrm{rpm}$. The product is then moved to a separating funnel to separate unreacted methanol and free fatty acid. The same procedure is repeated for the base catalyzed transesterification for another one hour using methanol and esterified soapnut oil in a molar ratio of $6: 1$. The reaction temperature of $60^{\circ} \mathrm{C}$ which is closer to the boiling point of methanol is selected and $\mathrm{KOH}$ concentration of $1 \%$ weight of oil was used. After the reaction is completed, the solution was allowed to settle for 24 Hours. The glycerin settles at the bottom, whereas the biodiesel was separated at the top and washed with warm water.

\subsection{Blend Preparation}

In the present work, low viscous pine oil was procured from the market, which is derived from the fresh needles, cones, resins and twigs of pine tree by steam distillation process. $75 \%$ vol. of neat pine oil was blended with $25 \%$ vol. of soapnut oil biodiesel to obtain the hybrid biofuel blend P75SNB25. A $20 \%$ vol. of soapnut oil biodiesel was blended with $80 \%$ vol. of diesel to obtain the blend SNB20. These two optimum fuel blend combinations were derived based on the previous research work by the authors (Venkatesan and Nallusamy 2020 ; Venkatesan et al. 2020) which offered improved performance and reduced exhaust emission except $\mathrm{NO}_{x}$. 
In the present investigation, the optimum blends P75SNB25 (Pine oil 75\% : Biodiesel 25\%) and SNB20 (Biodiesel 20\% : Diesel $80 \%$ ) were used in a twin cylinder tractor diesel engine to study its vibration and noise characteristics at different loads and the results were compared with diesel fuel operation.

\subsection{Fuel properties}

The physical and chemical properties of diesel, P100, SNB100, P75SNB25 and SNB20 were experimentally found as per ASTM standard. The fuel properties are listed in Table 1 and the nomenclature of test fuels were presented in Table 2. All the measuring instruments were calibrated before taking measurements for its accuracy.

Table 1

Properties of test fuels

\begin{tabular}{|llllll|}
\hline Test fuels & $\begin{array}{l}\text { Density at } \mathbf{1 5}^{\circ} \mathrm{C} \\
\left(\mathbf{k g} / \mathbf{m}^{3}\right)\end{array}$ & $\begin{array}{l}\text { Viscosity at } \mathbf{4 0}^{\circ} \mathrm{C} \\
\left(\mathbf{m m}^{2} \mathbf{s}\right)\end{array}$ & $\begin{array}{l}\text { Flash } \\
\text { point }\left({ }^{\circ} \mathrm{C}\right)\end{array}$ & $\begin{array}{l}\text { Calorific value } \\
(\mathbf{k J} / \mathbf{k g})\end{array}$ & $\begin{array}{l}\text { Cetane } \\
\text { Number }\end{array}$ \\
\hline $\begin{array}{l}\text { Standard } \\
\text { diesel (D100) }\end{array}$ & 832 & 3.42 & 52 & 40,290 & 53 \\
\hline P100 & 847 & 1.2 & 36 & 41,848 & 22 \\
\hline SNB100 & 868 & 3.60 & 158 & 37,723 & 56 \\
\hline P75SNB25 & 851 & 1.8 & 67 & 40,816 & 30 \\
\hline SNB20 & 839 & 3.46 & 73 & 39,776 & 53 \\
\hline $\begin{array}{l}\text { ASTM } \\
\text { standard }\end{array}$ & ASTM D1298 & ASTM D445 & $\begin{array}{l}\text { ASTM } \\
\text { D93 }\end{array}$ & ASTM D240 & - \\
\hline
\end{tabular}

Based on the researches carried out by the author using pine oil-soapnut oil biodiesel blends and dieselsoapnut oil biodiesel blends, the two optimum blends P75SNB25 and SNB20 were derived. From the table, it was noted that the heating value of P75SNB25 and the cetane number of SNB20 were highly competitive to diesel which enhances better performance and combustion (Venkatesan and Nallusamy 2020 ; Venkatesan et al. 2020).

Table 2

Nomenclature of test fuels

\begin{tabular}{|lllll|}
\hline Fuel & Diesel (Vol \%) & SNB (Vol \%) & Pine oil (Nol \%) & Resulting fuel \\
\hline Standard diesel (D100) & 100 & - & - & Base fuel \\
\hline P100 & - & - & 100 & Neat pine oil \\
\hline SNB100 & - & 100 & - & Neat biodiesel \\
\hline P75SNB25 & - & 25 & 75 & Hybrid biofuel \\
\hline SNB20 & 80 & 20 & - & Biodiesel blend \\
\hline
\end{tabular}




\subsection{Experimental setup and measurements}

A Simpson's S217 twin-cylinder, water cooled direct injection diesel engine was used for the investigation. The rated power of the test engine is $15 \mathrm{~kW}$ at $1500 \mathrm{rpm}$. An eddy current dynamometer of (Make \& model: Accurate test equipments - E50) is coupled with the engine for loading. The details of research engine and measuring instruments are tabulated (Table. 3 ).

Table 3

Test bed specifications

\begin{tabular}{|ll|}
\hline Make \& Model & Simpson's S217 \\
\hline Type & Inline DI diesel engine, naturally aspirated \\
\hline Cooling system & Water cooling \\
\hline No of cylinders & Two \\
\hline Bore x stroke & $91.44 \times 127 \mathrm{~mm}$ \\
\hline Compression ratio & $18.5: 1$ \\
\hline Rated power & $15 \mathrm{~kW}$ at $1500 \mathrm{rpm}$ \\
\hline Dynamometer & Eddy current \\
\hline Pressure pick up & Kistler 701A \\
\hline Accelerometer & Dytran 3053B \\
\hline Charge amplifier & DEWE-43A \\
\hline
\end{tabular}

The engine is instrumented with a tri-axial accelerometer transducer to measure the vibration signals. The accelerometer transducer (Make: Dytran 3053B) is mounted over the engine block using adhesive materials to measure the vibration acceleration along the axis of crank shaft $(X)$, the transverse axis $(Y)$ and along the cylinder axis ( $Z$ ). The transducer incorporates quartz sensing elements and packaged in light-weight titanium housing. Voltage signals were modulated by charge amplifier (DEWE-43A).

The Experimental setup for the test engine is shown in Fig. 1. An USB data acquisition system which uses the system software (DEWE soft) processes the input signals and generates time domain signals. Vibrations of time domains signals were converted in to frequency domain by Fast Fourier Transform (FFT). Microphone which is kept at a distance of one meter from the engine to obtain more accurate noise levels with the help of Dewe software.

\subsection{Experimental procedure}

In this study, the performance, combustion, vibration and acoustic characteristics were investigated in order to explore the effect of diesel (D100), P75SNB25 and SNB20. In order to bring the steady state in 
engine, the test engine was allowed to run for 20 minutes. Experiments were conducted at a rated speed of $1500 \mathrm{rpm}$ under $0 \%, 25 \%, 50 \%, 75 \%$ and $100 \%$ loading conditions to obtain engine performance, combustion, vibration and noise data. From the observed values of engine load, speed and time taken for $20 \mathrm{cc}$ fuel consumption, the performance parameters like brake thermal efficiency (BTE) and brake specific fuel consumption (BSFC) were calculated. The combustion characteristics like cylinder pressure and heat release rate were obtained by using the data acquisition system and Engine Performance Analyzer EPA 1.0.1. Vibration data was obtained by using a tri-axial, 8 channel accelerometer transducer and the collected data was analyzed by the data acquisition system which provides time domain signals and frequency domain signals using FFT. Error analysis was carried out to find out the uncertainty of various parameters like specific fuel consumption, brake power, brake thermal efficiency, cylinder pressure, exhaust gas temperature, vibration and noise. The total uncertainty of the present experiment was calculated using the formula derived by Holman (2012) and found to be $1.47 \%$.

\section{Results And Discussion}

\subsection{Performance analysis}

Brake thermal efficiency (BTE) and brake specific fuel consumption (BSFC) for the blends D100, P75SNB25 and SNB20 for various loads shown in Fig. 2. The combustion characteristics of soapnut oil biodiesel were enhanced by blending it with low viscous pine oil. The magnitude of BTE for D100, P75SNB25 and SNB20 at full load was recorded as 30.48\%, 31.52\% and 29.22\% respectively. From Fig. 2 it is observed that, for the blend P75SNB25, there is an enhancement in brake thermal efficiency at all loads and especially $3.50 \%$ enhancement at full load compared to diesel. The use of blend P75SNB25 resulted with the increase in brake thermal efficiency at all loads and especially. The heating value of P75SNB25 is found as $40,816 \mathrm{~kJ} / \mathrm{kg}$ which is higher than that of diesel $(40,290 \mathrm{~kJ} / \mathrm{kg})$. This results in lower specific fuel consumption and higher brake thermal efficiency for the blend at all loads.

The reduction in BTE by $3.3 \%$ and increase in BSFC by $1.35 \%$ was noted for the blend SNB20 at full load compared to diesel. The increase in BSFC of biodiesel- diesel blend is due to its lower energy content compared with that of the diesel fuel.

\subsection{Combustion analysis}

The cetane number, viscosity and oxygen content of the fuels have huge impact on ignition delay, combustion duration, cylinder peak pressure and heat release rate (Emiroglu and sen 2018). These are the most important parameters which affect the engine performance, emission and acoustic characteristics. Generally, the cylinder peak pressure increases with engine load. The variation of cylinder pressure for the test fuels at full load condition at the constant engine speed of $1500 \mathrm{rpm}$ is depicted in Fig. 3. From the pressure-crank angle diagram, a highest peak cylinder pressure of 88.6 bar was observed for diesel. The peak cylinder pressure of SNB20 was found to be 84.9 bar which is lower than that of diesel due to the lower heat energy released. For the blend P75SNB25, the peak cylinder pressure was 
observed as 87.96 bar which is almost closer to diesel due to its lower cetane number, slightly higher heating value and lower viscosity compared to diesel and SNB20. The heat release rate is an important combustion parameter used to predict the emission behavior of a fuel. Fig. 4 illustrates the variation of heat release rate in relation with crank angle at full load for different test fuels. The maximum heat release rate values are $62.5 \mathrm{~J} /{ }^{\circ} \mathrm{CA}, 65.02 \mathrm{~J} /{ }^{\circ} \mathrm{CA}$ and $58.7 \mathrm{~J} /{ }^{\circ} \mathrm{CA}$ for D100, P75SNB25 and SNB20 respectively. The higher heat release rate was observed for the pine oil blend because of its higher heating value and lower viscosity compared to diesel. The heat release pattern for the biofuel blends is similar to the heat release rate pattern for diesel at full load. The heat release rate was marginally negative during the ignition delay period due to the cooling effect of freshly injected fuel.

Figure 5 shows the variation of exhaust gas temperature (EGT) for D100, P75SNB25 and SNB20 at different loads. For all the test fuels, the EGT increases with increase in engine load. EGT of the biofuel blends is greater than diesel at all loads. The exhaust gas temperature for D100, P75SNB25 and SNB20 was found to be $512^{\circ} \mathrm{C}, 514^{\circ} \mathrm{C}$ and $516^{\circ} \mathrm{C}$ respectively at full load. This increase in EGT is due to the oxygenated nature of the biofuel blends and improved combustion.

\subsection{Vibration and Noise analysis}

Combustion induced vibration is considered as one of the major drawback associated with the diesel engine and this can be reduced by use of biofuels. The vibration acceleration is measured in $\mathrm{m} / \mathrm{s}^{2}$. Engine vibration is an undesirable thing which increased stress on engine parts resulting in wear and noise. The vibration and noise level depends upon the engine load and speed. Vibration frequency data of up to $10 \mathrm{kHz}$ can be obtained using the present accelerometer. Considering the engine speed of $1500 \mathrm{rpm}$, one cycle of operation is completed in $0.08 \mathrm{sec}$ to produce one power stroke and an acceleration peak. Hence, vibration were obtained (in time domain mode) at the determined sampling frequency of $0.10 \mathrm{sec}$. The number of data within the time period was 1280. The Fig. 6 shows the total vibration acceleration with respect to time for diesel, P75SNB25 and SNB20 at no load and full load. Fig. 7 and Fig. 8 show the total vibration acceleration with respect to frequency for diesel, P75SNB25 and SNB20 at no load and full load condition respectively. The maximum amplitude of acceleration was observed as $19.97 \mathrm{~m} / \mathrm{s}^{2}$ for diesel at no load (Fig. 6a) and $48.07 \mathrm{~m} / \mathrm{s}^{2}$ at full load condition (Fig. 6b). Experimental results showed that the biofuel blends generated least vibrations compared to diesel at both no load and full load. For the blend P75SNB25 the amplitude of acceleration was recorded as $16.08 \mathrm{~m} / \mathrm{s}^{2}$ which is $19.48 \%$ lower than diesel at no load condition (Fig. 6c). The peak value of acceleration for the blend was recorded as $42.5 \mathrm{~m} / \mathrm{s}^{2}$ at full load (Fig. 6d) which is $11.58 \%$ lower than diesel.

Whereas, the amplitude of acceleration for the blend SNB20 was observed as $17.12 \mathrm{~m} / \mathrm{s}^{2}$ and $43.52 \mathrm{~m} / \mathrm{s}^{2}$ at no load (Fig. 6e) and full load (Fig. 6f) respectively. The reduction in $14.27 \%$ and $9.46 \%$ was recorded for the blend at no load and full load compared to diesel operation. This reduction in engine vibration for the biofuel blends is the indication of improved combustion. The ignition quality of biofuel and the excess oxygen present in it leads to smoother combustion process resulting in reduced vibration. Some 
other factors which reduced the vibration are advanced injection timing, viscosity and cetane number pertaining to the biodiesel blends (Taghizadeh et al. 2012).

At the engine speed of $1500 \mathrm{rpm}$, one peak value of vibration acceleration occurs for every $25 \mathrm{~Hz}$ as the engine combustion frequency is $25 \mathrm{~Hz}$. The total amplitude of acceleration is the sum of combustion shock and valve seating vibrations (Yang et al 2018). Hence, the vibration acceleration was recorded for a sampling frequency of $500 \mathrm{~Hz}$ (20 times of the combustion frequency) by which about 20 combustion peaks can be recorded. Fig. 7 and Fig. 8 show the vibration acceleration for the test fuels as a function of frequency at no load and full load condition respectively. For D100, the vibration peak was observed as $0.434 \mathrm{~g}$ and $0.651 \mathrm{~g}$ at no load and full load condition respectively at the engine combustion frequency of $87.50 \mathrm{~Hz}$. For the blend P75SNB25, the vibration peak was observed as $0.383 \mathrm{~g}$ at the combustion frequency of $81.25 \mathrm{~Hz}$ in no load condition and $0.727 \mathrm{~g}$ at the frequency of $87.50 \mathrm{~Hz}$ in full load condition. For the blend SNB20, the vibration peak was observed as $0.446 \mathrm{~g}$ and $0.502 \mathrm{~g}$ at no load and full load condition respectively at the engine combustion frequency of $87.50 \mathrm{~Hz}$. From the results it was concluded that the blend P75SNB25 offered the lowest vibration peak at no load and the blend SNB20 offered lowest vibration peak at full load compared to diesel.

Noise level in the internal combustion engines depends upon the cylinder peak pressure and heat release rate (Ghaderi et al. 2019). In-cylinder pressure generated inside the combustion chamber causes vibrations in the engine block which results in noise to the environment. Fig. 9 shows the variation in engine noise level at different loads for the test fuel. The noise level was recorded as $102.41 \mathrm{~dB}, 101.05$ dB and $101.23 \mathrm{~dB}$ for D100, P75SNB25 and SNB20 respectively at no load. The noise level increases as the engine load increases. The magnitude of noise value for D100, P75SNB25 and SNB20 was recorded as $104.47 \mathrm{~dB}, 103.18 \mathrm{~dB}$ and $103.90 \mathrm{~dB}$ respectively at full load condition. The results revealed that the noise level for the biofuel blends shown a reduction because of the smoother combustion and lower cylinder peak pressure.

\section{Conclusions}

In this study, the effects of novel hybrid biofuel blend (P75SNB25) and conventional diesel- biodiesel blend (SNB20) on engine performance, combustion, vibration and noise in a tractor diesel engine were investigated. From the experimental results, the increase in BTE for the blend P75SNB25 by $3.50 \%$ and decrease in BTE for the blend SNB20 by 3.3\% were observed at full load operation compared to diesel fuel. The exhaust gas temperature for the blends was higher than diesel at all the engine loads. For the blend P75SNB25, the amplitude of acceleration with respect to time was reduced by $19.48 \%$ and $11.58 \%$ at no load and full load respectively. For the blend SNB20, the amplitude of acceleration showed a reduction by $14.27 \%$ and $9.46 \%$ at no load and full load respectively compared to diesel. The noise emission of the biofuel blends was decreased up to a maximum of $1.87 \%$ at the entire load range compared to baseline diesel due to the smoother combustion. From the experimental investigations, it was concluded that the blends P75SNB25 and SNB20 had shown better results in terms of vibration and 
noise with the blend P75SNB25 has a slight edge over SNB20 in terms of engine performance and combustion.

\section{Declarations}

\section{Author contribution:}

V. Venkatesan: Initial idea, Sampling, Laboratory activity, Conceptualization, Methodology, Investigation, Interpretation, Writing, Review and Editing.

N. Nallusamy: Conceptualization, Interpretation, Review and Editing.

P. Nagapandiselvi: Laboratory activity, Investigation, Review and Editing.

Funding : Not applicable

Data availability of data and Materials: All data generated or analyzed during this study are included in this published article.

\section{Declarations :}

Ethics approval : Not applicable

Consent to participate : All the authors consented to participate in the drafting of this manuscript.

Consent for publication: All the authors consented to publish this manuscript..

Competing interests: The authors declare no competing interests

\section{References}

1. Barelli L, Bidini G, Buratti C, Mariani R (2009) Diagnosis of internal combustion engine through vibration and acoustic pressure non-intrusive measurements. Appl Therm Eng 29:1707-1713

2. Calık A (2018) Determination of vibration characteristics of a compression ignition engine operated by hydrogen enriched diesel and biodiesel fuels. Fuel 230:355-358

3. Carlucci AP, Chiara FF, Laforgia D (2005) Analysis of the relation between injection parameter variation and block vibration of an internal combustion diesel engine. J sound vib 295:141-164

4. Celebi K, Uludamar E, Ozcanli M (2017) Evaluation of fuel consumption and vibration characteristic of a compression ignition engine fuelled with high viscosity biodiesel and hydrogen addition. Int $J$ Hydrogen Energy.23379-23388

5. Chen Yi-H, Tang T-C, Chiang T-H, Huang B-Y, Chang C-Y, Chiang P-C, Shie J-L, Franzreb M, Chen L-Y (2012) A complementary Biodiesel Blend from Soapnut Oil and Free Fatty Acids. Energies 5(8):3137-3148 
6. Chiatti G, Chiavolal O, Palmieri F (2016) Vibration and acoustic characteristics of a city-car engine fueled with biodiesel blends. Appl Energy 185:664-670

7. Emiroglu AO, Sen M (2018) Combustion, performance and exhaust emission characterizations of a diesel engine operating with a ternary blend (alcohol-biodiesel-diesel fuel). Appl Therm Eng 133:371380

8. Ghaderi M, Javadikia H, Naderloo L, Mostafaei M, Rabbani H (2019) An analysis of noise pollution emitted by moving MF285 Tractor using different mixtures of biodiesel, bioethanol and diesel through artificial intelligence. Journal of Low Frequency Noise, Vibration and Active Control 38(2):270-281

9. Holman JP (2012) Experimental Methods for Engineers, 8th edition, McGraw-Hill, Inc., New York, NY, USA

10. How HG, Masjuki HH, Kalam MA, Teoh YH (2014) An investigation of the engine performance, emissions and combustion characteristics of coconut biodiesel in a high-pressure common-rail diesel engine. Energy 69:749-759

11. Javed S, Satyanarayana Murthy YVV, Baig RU, Nagarjuna Rao T (2016) Vibration analysis of a diesel engine using biodiesel fuel blended with nano particles by dual fueling of hydrogen. J Nat Gas Sci Eng 33:217-230

12. Sarıdemir S, Agbulut U (2019) Combustion, performance, vibration and noise characteristics of cottonseed methyl ester-diesel blends fuelled engine,Biofuels,1-10

13. Silva SS, Chandel AK (2014) Biofuels in Brazil. Fundamental Aspects, Recent Developments, and Future Perspectives. Springer Science \& Business Media, São Paulo

14. Taghizadeh AA, Ghobadian B, Tavakoli HT, Mohtasebi SS (2012) Vibration analysis of a diesel engine using biodiesel and petrol diesel fuel blends. Fuel 102:414-422

15. Tuccar $\mathrm{G}$ (2018) Experimental study on vibration and noise characteristics of a diesel engine fueled with mustard oil biodiesel and hydrogen gas mixture.Biofuels, $1-6$

16. Uludamar E, Tosun E, Tuccar G, yilidizhan S, Calik A, Yildirim S, Serin H, Ozcanli M, (2017) Evaluation of vibration characteristics of a hydroxyl $(\mathrm{HHO})$ gas generator installed diesel engine fuelled with different diesel-biodiesel blends.Int. J. Hydrogen Energy, 42 (36):23352-23360

17. Venkatesan V, Nallusamy N (2020) Pine oil-soapnut oil methyl ester blends: A hybrid biofuel approach to completely eliminate the use of diesel in a twin cylinder off-road tractor diesel engine. Fuel 262:116500

18. Venkatesan V, Nallusamy N, Nagapandiselvi P (2020) Waste-to-Energy Approach for Utilizing Nonedible Soapnut Oil Methyl Ester as a Fuel in a Twin-Cylinder Agricultural Tractor Diesel Engine. Energy Fuels 34:1958-1964

19. Yang T, Wang T, Li G, Shi J, Sun X (2018) Vibration Characteristics of Compression Ignition Engines Fueled with Blended Petro-Diesel and Fischer-Tropsch Diesel Fuel from Coal Fuels, Energies. 11: 2043 
Figures

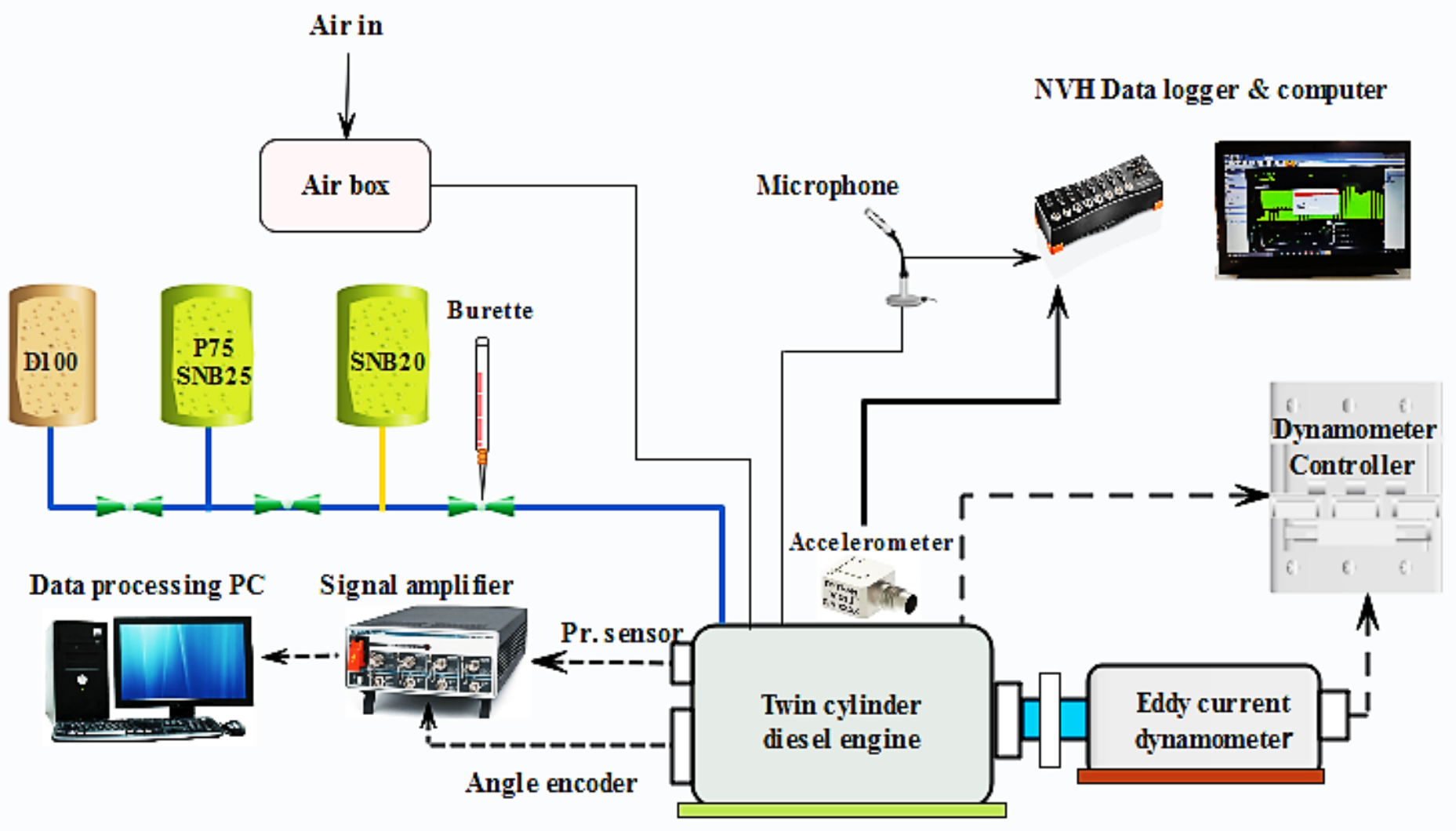

Figure 1

Experimental setup of the test engine 


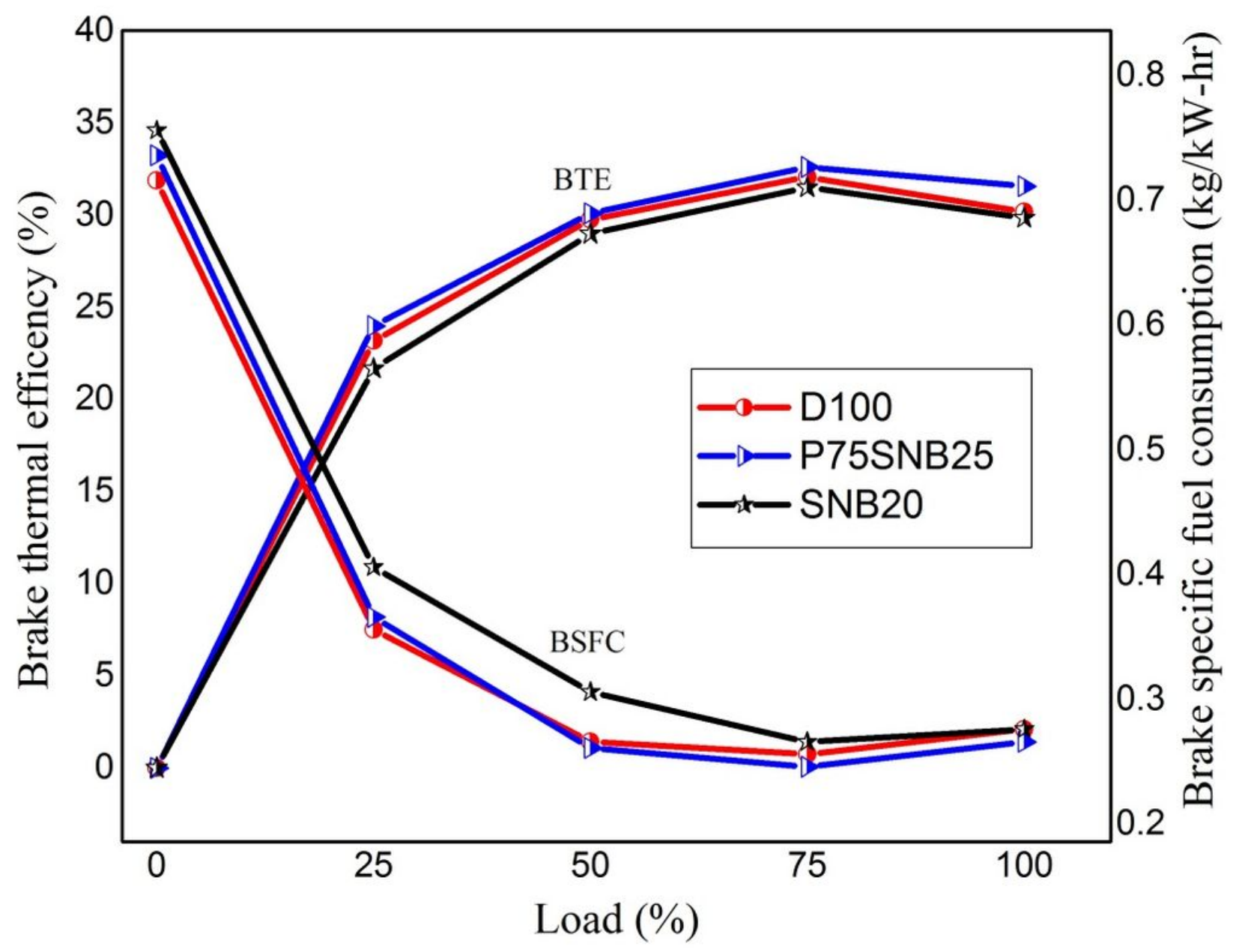

Figure 2

The variation of engine performance parameters with load 


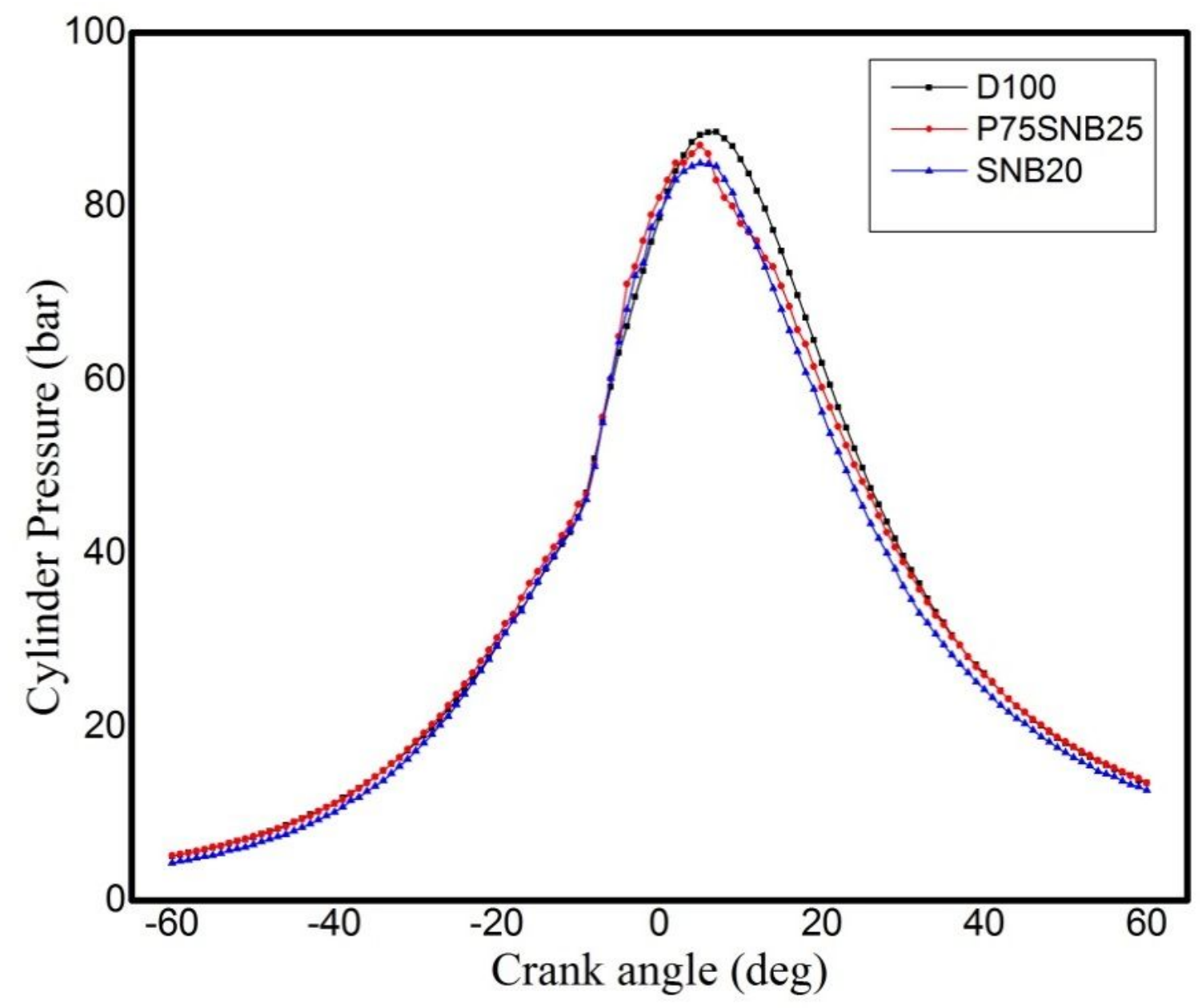

Figure 3

The variation of cylinder peak pressure in relation with crank angle

Figure 4

The variation of heat release rate with crank angle at full load 


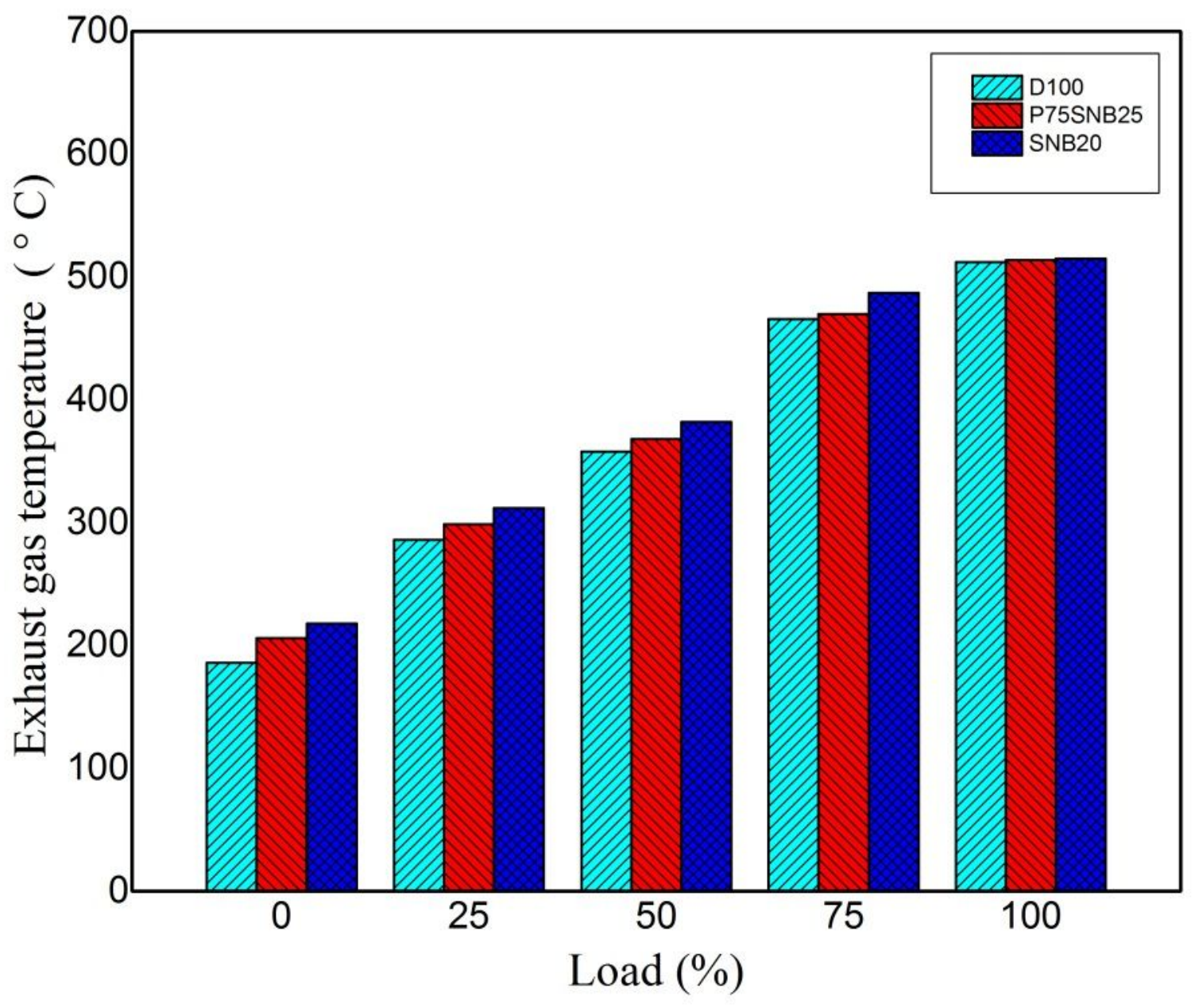

Figure 5

The variation of exhaust gas temperature with engine load

Figure 6

Time Vs Acceleration at No load and full load

Figure 7 
Frequency Vs Acceleration at No load

Figure 8

Frequency Vs Acceleration at Full load

Figure 9

The variation of noise level with load 